\title{
Berberine hydrochloride inhibits cell proliferation and promotes apoptosis of non-small cell lung cancer via the suppression of the MMP2 and Bcl-2/Bax signaling pathways
}

\author{
JIE LI $^{1 *}$, FANG LIU ${ }^{2 *}$, SHULONG JIANG ${ }^{1}$, JIE LIU $^{3}$, XIUHONG CHEN $^{1}$, \\ SHANGNUAN ZHANG ${ }^{1}$ and HAIBO ZHAO ${ }^{1}$
}

${ }^{1}$ Department of Oncology, Jining First People's Hospital, Jining, Shandong $272011 ;{ }^{2}$ Department of
Oncology, Dongying City People's Hospital, Dongying; ${ }^{3}$ Department of Oncology, Shandong Cancer
Hospital and Institute Shandong Academy of Medical Sciences, Jinan, Shandong 257091, P.R. China

Received November 9, 2015; Accepted January 11, 2017

DOI: $10.3892 / \mathrm{ol} .2018 .8249$

\begin{abstract}
Berberine, also known as berberine hydrochloride and isoquinoline alkaloid, is a major alkaloid from Coptis chinensis. Berberine's extensive biological properties have previously been studied, and it has been used clinically for the treatment of diarrhea, hypertension, diabetes and other diseases. The present study aimed to determine the possible anticancer effects of berberine hydrochloride treatment on human non-small cell lung cancer (NSCLC) cell proliferation and apoptosis via the matrix metalloproteinase 2 (MMP-2) and the B-cell lymphoma 2 (Bcl-2)/Bcl-2-associated $\mathrm{X}$ protein (Bax) signaling pathway. Human A549 lung carcinoma cells were exposed to various concentrations of berberine hydrochloride in order to analyze the possible anticancer effects on NSCLC cell proliferation and apoptosis, using a MTT assay and an Annexin V-fluorescein isothiocyanate/propidium iodide apoptosis kit. Subsequently, the present study detected the expression of MMP-2, Bcl-2, Bax and Janus kinase 2 (Jak2). Berberine hydrochloride treatment inhibited the expression of vascular endothelial growth factor (VEGF) and nuclear factor $\kappa \mathrm{B}(\mathrm{NF}-\kappa \mathrm{B})$ and transcription factor AP-1 (AP-1) proteins, in A549 cells. Firstly, it was revealed that berberine hydrochloride treatment may inhibit proliferation, increase cytotoxicity and enhance apoptosis in A549 cells. Subsequently, treatment with berberine hydrochloride significantly downregulated MMP-2 protein expression, increased
\end{abstract}

Correspondence to: Dr Haibo Zhao, Department of Oncology, Jining First People's Hospital, 6 Jiankang Road, Jining, Shandong 272011, P.R. China

E-mail: qqhaibozhao@163.com

*Contributed equally

Key words: berberine hydrochloride, non-small cell lung cancer, matrix metalloproteinase 2, B-cell lymphoma 2/B-cell lymphoma 2 -associated $\mathrm{X}$ protein the activity of the $\mathrm{Bcl}-2 / \mathrm{Bax}$ signaling pathway and suppressed the Jak2/VEGF/NF-kB/AP-1signaling pathways. These results suggest that berberine hydrochloride may be a potential novel anticancer drug, since it inhibits cell proliferation and promotes the rate of apoptosis of NSCLC cells by the suppression of the MMP-2, Bcl-2/Bax and Jak2/VEGF/NF-кB/AP-1 signaling pathways.

\section{Introduction}

According to a previous study, $3,120,000$ novel cases of cancer are identified in China annually, which is equivalent to $\sim 8,550$ patients being diagnosed with cancer every day or 5 patients/min on average (1). Lung cancer is one of the most common types of malignant tumors of the respiratory system, and has the highest rates of incidence and mortality of malignant tumors $(1,2)$. Non-small cell lung cancer (NSCLC) is a common type of cancer. Numerous previous studies have confirmed that the leading cause of mortality for patients with lung cancer is metastasis. The prevention of metastasis is therefore the focus of lung cancer treatment (3-5).

Angiogenesis serves an important role in tumor growth and metastasis (6). The induction of angiogenesis requires the angiogenesis phenotype of lung cancer tumor cells (7). Angiogenesis induction also requires the promotion of tumor angiogenesis factors using inhibiting factors; vascular endothelial growth factor (VEGF) is the primary regulating factor of angiogenesis, and serves an important role in the development, invasion and metastasis of lung cancer (8). Matrix metalloproteinases (MMPs) are a group of metal ion-dependent proteases, which are able to degrade the various proteins in the basement membrane and extracellular membrane (ECM), thus promoting the invasion and metastasis of lung cancer to adjacent and distant tissues (9). A previous study indicated that MMPs and VEGF are closely associated with the occurrence, development, invasion, metastasis and prognosis of lung cancer (10).

According to a previous study on the effect of berberine hydrochloride on tumor cells, it has been revealed that this compound exhibits cytotoxicity, and is able to inhibit the 
growth and proliferation of tumor cells (11). Berberine hydrochloride may inhibit the proliferation of colon, gastric, breast, esophageal and liver cancer cells $(12,13)$. The inhibitory effect previously demonstrated was revealed to be dose and time-dependent in a number of studies (14-16). The effects of numerous treatment concentrations of berberine hydrochloride on various cellular locations and stages of the cell cycle in a human melanoma cell line were investigated. A previous study revealed that a low dose of berberine hydrochloride may be concentrated in mitochondria and inhibit the growth of melanoma cells in the $G_{1}$ phase cell cycle (17). A high dose of berberine hydrochloride may promote the accumulation of melanin tumor cells in the $G_{2}$ phase and inhibit the synthesis of DNA, whereas a low dose of berberine may not affect the synthesis of DNA (18). Furthermore, the present study investigated the inhibition of cell proliferation and the promotion of apoptosis induced by the berberine hydrochloride treatment of NSCLC cells, which was induced by the suppression of MMP-2 and the Bcl-2/Bax signaling pathway.

\section{Materials and methods}

Materials and the cell line. Human NSCLC A549 cells were obtained from The Cell Bank of Type Culture Collection of Chinese Academy of Sciences (Shanghai, China) and cultured in Dulbecco's modified Eagle's medium (Cellgro; Corning Incorporated, Corning, NY, USA) supplemented with $10 \%$ fetal bovine serum (Gibco; Thermo Fisher Scientific, Inc.), $100 \mathrm{U} / \mathrm{ml}$ penicillin and $100 \mu \mathrm{g} / \mathrm{ml}$ streptomycin, in a humidified atmosphere with $5 \% \mathrm{CO}_{2}$ at $37^{\circ} \mathrm{C}$. The chemical structure of berberine hydrochloride (Sigma-Aldrich; Merck Millipore, Darmstadt, Germany) is presented in Fig. 1.

Proliferation assay. A549 human NSCLC cells were seeded at a density of $5 \times 10^{3}$ cells/well in 96-well culture plates and treated with various concentrations $(0,30,60,90,150$ and $200 \mu \mathrm{M})$ of berberine hydrochloride at $37^{\circ} \mathrm{C}$ for $0,1,2$ and 3 days. A total of $150 \mu \mathrm{l}$ MTT (Invitrogen; Thermo Fisher Scientific, Inc.) was added to each well and incubated for $4 \mathrm{~h}$ at $37^{\circ} \mathrm{C}$. A total of $150 \mu \mathrm{l}$ dimethyl sulfoxide (Invitrogen; Thermo Fisher Scientific, Inc.) was then added to each well for $10 \mathrm{~min}$ at $37^{\circ} \mathrm{C}$ with agitation. The absorbance was evaluated using a Varioskan Flash microplate reader (Thermo Fisher Scientific, Inc.) at 450 and $630 \mathrm{~nm}$.

Cell apoptosis detection. A549 human NSCLC cells were seeded at a density of $2 \times 10^{6}$ cells/well in 96-well culture plates and treated with various concentrations $(30,60$ and $90 \mu \mathrm{M})$ berberine hydrochloride at $37^{\circ} \mathrm{C}$ for 2 days. The cells were subsequently harvested by careful trypsinization without EDTA, and washed twice with PBS. Subsequently, the cells were harvested using $10 \mu \mathrm{l}$ Annexin $\mathrm{V}$ binding buffer and stained with Annexin V-fluorescein isothiocyanate $/ 5 \mu$ propidium iodide (PE Annexin V Apoptosis Detection kit I, BD Biosciences, Franklin Lakes, NJ, USA) at $4^{\circ} \mathrm{C}$ for $15 \mathrm{~min}$ at darkness. Flow cytometry was performed using a FACS-420 flow cytometer (BD Biosciences) in order to analyze the rate of cell apoptosis.

Western blotting. A549 human NSCLC cells were seeded at a density of $2 \times 10^{6}$ cells/well in 96-well culture plates and treated with various concentrations $(30,60$ and $90 \mu \mathrm{M})$ of berberine hydrochloride at $37^{\circ} \mathrm{C}$ for 2 days. Subsequently, the cells were harvested and lysed with lysis buffer (RIPA assay, Beyotime Institute of Biotechnology, Haimen, China) at $4^{\circ} \mathrm{C}$ for $15 \mathrm{~min}$. The supernatant was centrifuged at $12,000 \times \mathrm{g}$ for $15 \mathrm{~min}$ at $4^{\circ} \mathrm{C}$. The soluble protein concentration was determined using a Bradford assay (Beyotime Institute of Biotechnology, Haimen, China). Protein samples were separated by SDS-PAGE (8-12\%) and transferred onto a polyvinylidene fluoride membrane by wet transfer. The membranes were blocked with $1 \%$ Tween-20 PBS (TBST) at $4^{\circ} \mathrm{C}$ overnight prior to incubation with anti-MMP-2 (cat. no. sc-13594; dilution, 1:2,000), anti-Bax (cat. no. sc-20067; dilution, 1:2,000), anti-Bcl-2 (cat. no. sc-7382; dilution, 1:2,000, anti-Janus kinase 2 (Jak2) (cat. no. sc-390539; dilution, 1:2,000), anti-VEGF (cat. no. sc-390741; dilution, 1:2,000), anti-NF-кB/p65 (cat. no. sc-372; dilution, 1:2,000) and anti-transcription factor AP-1 (AP-1; cat. no. sc-12629; dilution, 1:2,000; all from Santa Cruz Biotechnology, Inc., Dallas, TX, USA), and $\beta$-actin (cat. no. D110007; dilution, 1:2,000, Shanghai Sangon Pharmaceutical Co., Ltd., Shanghai, China). Following washing with TBST, the membranes were incubated with anti-rabbit IgG-HRP (cat. no. sc-2357, dilution, 1:3,000, Santa Cruz Biotechnology, Inc.) at $37^{\circ} \mathrm{C}$ for $1 \mathrm{~h}$ and visualized using an ECL Prime kit (Merck Millipore).

Statistical analysis. The data are presented as the mean \pm standard error of the mean, which was determined using SPSS 19.0 software (IBM SPSS, Armonk, NY, USA). The paired t-test and one-way analysis of variance were performed in order to determine the statistical significance between various groups. $\mathrm{P}<0.05$ was considered to indicate a statistically significant difference.

\section{Results}

Berberine hydrochloride inhibits the proliferation of A549 cells. In order to determine the anticancer effect of berberine hydrochloride on the proliferation of A549 cells, the cells were treated with a variety of concentrations of berberine hydrochloride. As presented in Fig. 2, berberine hydrochloride suppressed the growth of cells in a time- and dose-dependent manner. Following a 48-h treatment, $60-200 \mu \mathrm{M}$ of berberine hydrochloride effectively suppressed the proliferation of A549 cells, compared with the control group (Fig. 2). However, 90-200 $\mu \mathrm{M}$ berberine hydrochloride treatments effectively suppressed the proliferation of A549 cells following $24 \mathrm{~h}$ (Fig. 2).

Berberine hydrochloride promotes the apoptosis of A549 cells. Further analysis demonstrated that berberine hydrochloride dose-dependently promote the apoptosis of A549 cells (Fig. 3). Berberine hydrochloride treatment at concentrations of 60 and $90 \mu \mathrm{M}$ for $24 \mathrm{~h}$ effectively induced the apoptosis of A549 cells (Fig. 3; $\mathrm{P}=0.0056$ and $\mathrm{P}=0.0031$, respectively).

\section{Berberine hydrochloride inhibits MMP-2 protein expression} in A549 cells. In order to evaluate the association between the anticancer effect of berberine hydrochloride and MMP-2 expression level in A549 cells, western blotting was performed. As indicated in Fig. 4, $90 \mu \mathrm{M}$ berberine hydrochloride 


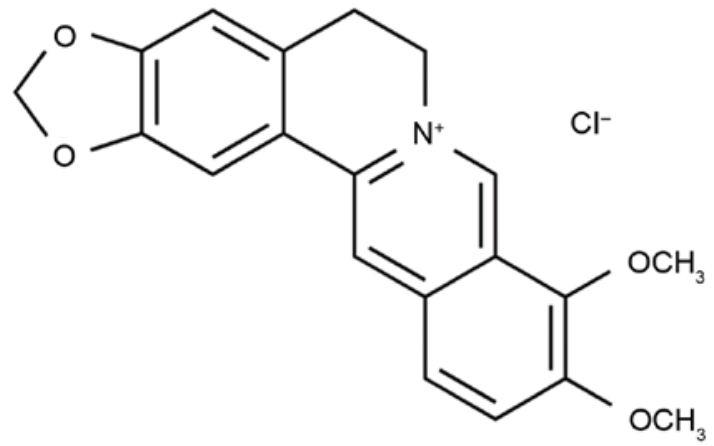

Figure 1. The chemical structure of berberine hydrochloride.

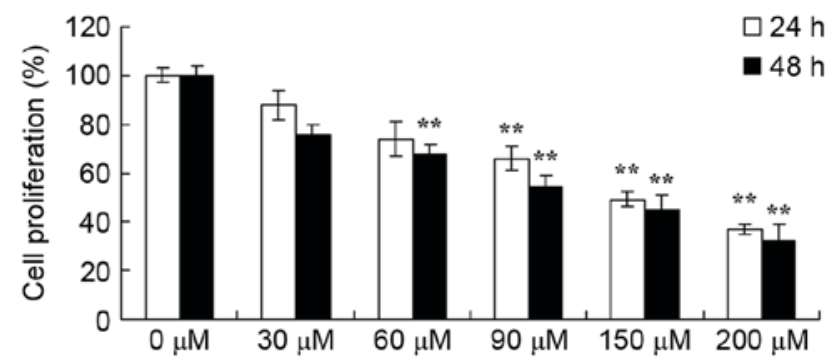

Figure 2. Berberine hydrochloride treatment inhibits the proliferation of A549 cells. ${ }^{* *} \mathrm{P}<0.01$, compared with the $0 \mu \mathrm{M}$ berberine hydrochloride treatment group (control group).

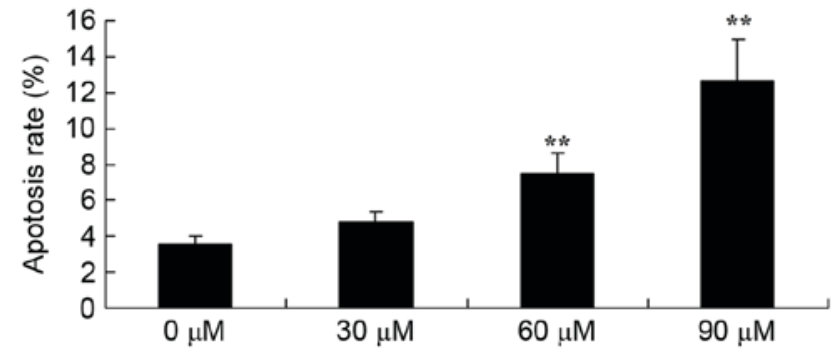

Figure 3. Berberine hydrochloride treatment promotes the apoptosis of A549 cells. ${ }^{* *} \mathrm{P}<0.01$, compared with the $0 \mu \mathrm{M}$ berberine hydrochloride treatment group.

treatments significantly inhibited the MMP-2 protein expression level in A549 cells following $24 \mathrm{~h}$, compared with control group $(\mathrm{P}=0.0074)$.

Berberine hydrochloride promotes the Bcl-2/Bax signaling pathway in A549 cells. In order to determine the association between the anticancer effect of berberine hydrochloride on lung cancer cells and the Bcl-2/Bax signaling pathway, Bax and Bcl-2 protein expression levels were evaluated using western blot analysis. Treatment with 60 and $90 \mu \mathrm{M}$ berberine hydrochloride significantly increased the activity of the Bcl-2/Bax signaling pathway in A549 cells, compared with control group (Fig. 5; $\mathrm{P}=0.0047$ and $\mathrm{P}=0.0025$, respectively).

Berberine hydrochloride inhibits Jak2 protein expression in A549 cells. In order to determine the anticancer effect of berberine hydrochloride treatment on the protein expression levels of the apoptosis signaling molecules, A549 cells were treated with berberine hydrochloride for $24 \mathrm{~h}$ and analyzed using western blotting. It was revealed that berberine hydrochloride treatment at 60 and $90 \mu \mathrm{M}$ significantly inhibited Jak2 protein expression level in A549 cells, compared with control group (Fig. 6; $\mathrm{P}=0.0082$ and $\mathrm{P}=0.0068$, respectively).

Berberine hydrochloride inhibits VEGF protein expression level in A549 cells. In order to determine the association between the VEGF signaling pathway and the anticancer effect of berberine hydrochloride on lung cancer, changes in expression of VEGF protein were analyzed following treatment of A549 cells with various concentrations $(0-90 \mu \mathrm{M})$ of berberine hydrochloride. As presented in Fig. 7, VEGF expression was significantly inhibited following treatment with 60 and $90 \mu \mathrm{M}$ berberine hydrochloride $(\mathrm{P}=0.0061$ and $\mathrm{P}=0.0028$, respectively).

Berberine hydrochloride inhibits $N F-\kappa B$ protein expression in A549 cells. In order to confirm the anticancer effect of berberine hydrochloride on $\mathrm{NF}-\kappa \mathrm{B}$ protein expression levels in A549 cells, NF- $\kappa \mathrm{B} / \mathrm{p} 65$ protein expression levels were determined by western blot analysis. As indicated in Fig. 8, $\mathrm{NF}-\kappa \mathrm{B} / \mathrm{p} 65$ protein expression level was significantly inhibited by 60 and $90 \mu \mathrm{M}$ berberine hydrochloride treatment for $24 \mathrm{~h}$, compared with the control group $(\mathrm{P}=0.0045$ and $\mathrm{P}=0.0017$, respectively).

Berberine hydrochloride inhibitsAP-1 protein expression in A549 cells. In order to determine the association between the anticancer effect of berberine hydrochloride and the AP-1 signaling pathway in A549 cells, the effect of berberine hydrochloride on AP-1 protein expression was evaluated. As indicated in Fig. 9, pre-incubation with berberine hydrochloride significantly increased the rate of apoptosis in A549 cells via suppression of the AP-1 signaling pathway, compared with the control group $(\mathrm{P}=0.0089$ and $\mathrm{P}=0.0055)$.

\section{Discussion}

NSCLC is a threat to human health and life (10). The morbidity and mortality rates of NSCLC have significantly increased worldwide over the past 50 years, and the disease is a major type of cancer (19). Previously, studies have revealed that the occurrence of NSCLC is closely associated with the inactivation of certain oncogene and tumor-suppressor genes (20). The overexpression of oncogenes, the downregulation of tumor-suppressor genes and the decreased rate of apoptosis may induce the malignant transformation of cells (21). The results of the present study have demonstrated that berberine hydrochloride inhibits cell proliferation and promotes the apoptosis of A549 cells. Certain studies have revealed that berberine suppresses the growth of MCF-7 breast cancer cells, colon cancer and ovarian cancer cells (22-24).

MMP-2 and MMP-9 are gelatinases belonging to the MMP family (25). They are able to degrade the constitutive proteins in the ECM and basement membrane, and gather on the surface of collagen IV (25). MMPs contribute to the loss of basement membrane by degrading the ECM and basement membrane, which then allows tumor cells to spread and infiltrate into the adjacent tissues through the loose ECM and the absent basement membrane, eventually contributing to 
A

MMP-2

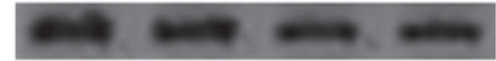

$\beta$-actin

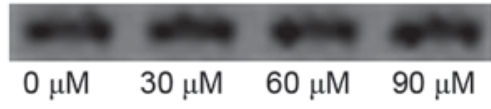

B

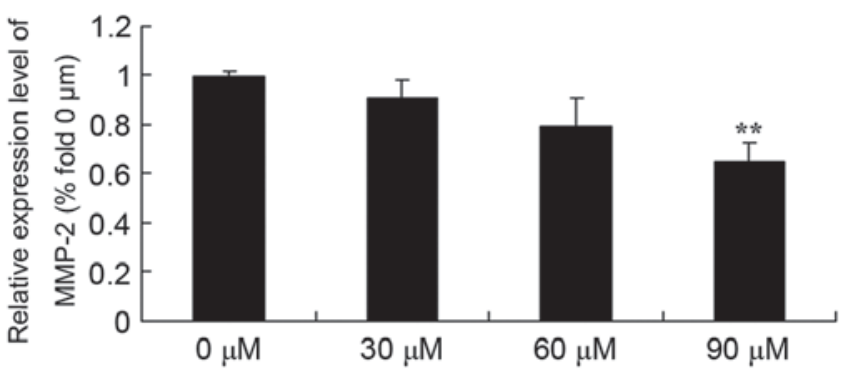

Figure 4. Berberine hydrochloride treatment inhibits the expression level of MMP-2 in A549 cells. Western blot analysis and statistical analysis of MMP-2 expression levels in berberine hydrochloride-treated A549 cells. ${ }^{* *} \mathrm{P}<0.01$, compared with the $0 \mu \mathrm{M}$ berberine hydrochloride treatment group. MMP-2, matrix metalloproteinase 2 .

A

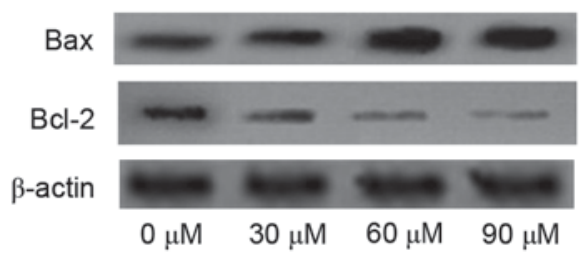

B

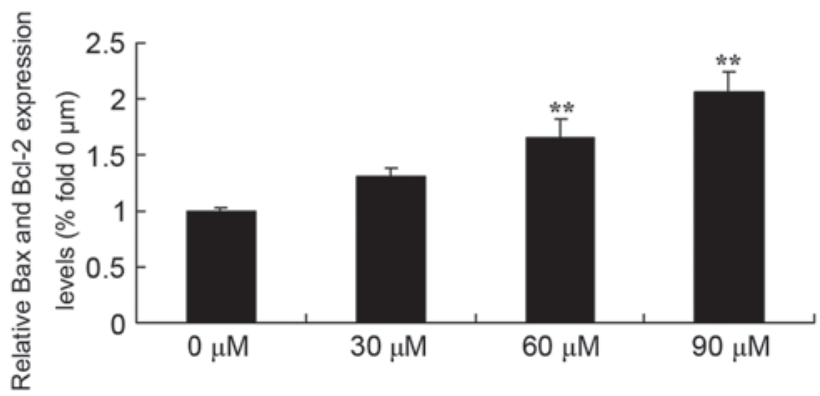

Figure 5. Berberine hydrochloride treatment promotes Bcl-2 and Bax protein expression levels in A549 cells. Western blotting and statistical analysis revealed that berberine hydrochloride treatment increased Bax and Bcl-2 protein expression levels in berberine hydrochloride treated A549 cells. ${ }^{* *} \mathrm{P}<0.01$, compared with the $0 \mu \mathrm{M}$ berberine hydrochloride treatment group. Bcl-2, B-cell lymphoma 2; Bax, Bcl-2-associated X protein.
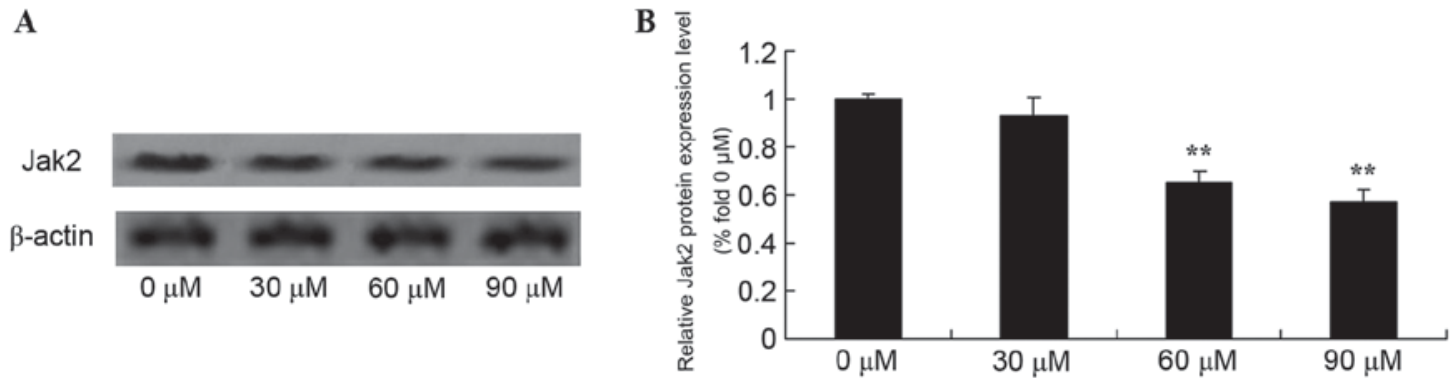

Figure 6. Berberine hydrochloride treatment inhibits the expression of Jak2 in A549 cells. Western blotting and statistical analysis were performed in order to evaluate the expression level of Jak2 in berberine hydrochloride treated A549 cells. ${ }^{* *} \mathrm{P}<0.01$, compared with the $0 \mu \mathrm{M}$ berberine hydrochloride treatment group. Jak2, Janus kinase 2.

A

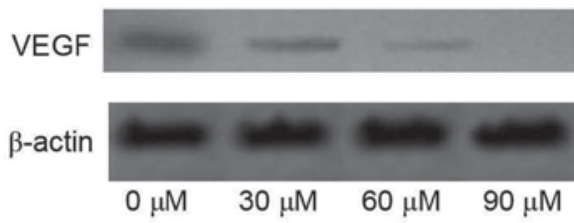

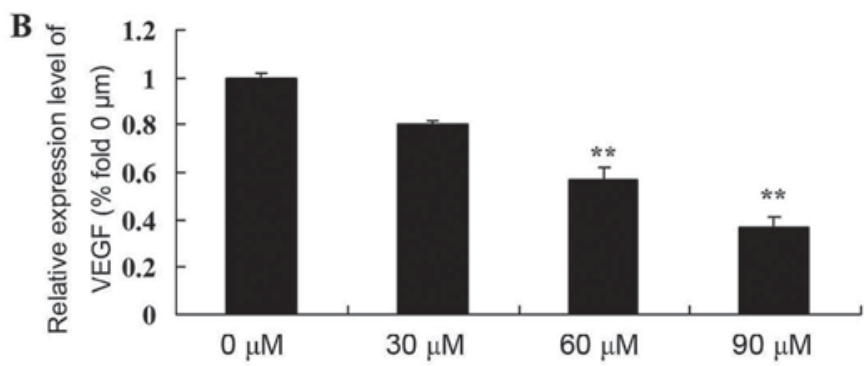

Figure 7. Berberine hydrochloride treatment inhibits the expression of VEGF protein in A549 cells. Western blotting and statistical analysis evaluated the VEGF protein expression levels in berberine hydrochloride treated A549 cells. ${ }^{* *} \mathrm{P}<0.01$, compared with the $0 \mu \mathrm{M}$ berberine hydrochloride treatment group. VEGF; vascular endothelial growth factor.

the invasion and metastasis of lung tumors $(26,27)$. Previous studies also indicated that MMP-2 or MMP-9 may promote the growth of blood vessels and lymphatic vessels by enhancing the binding of VEGF to VEGF receptors, thus promoting 
A

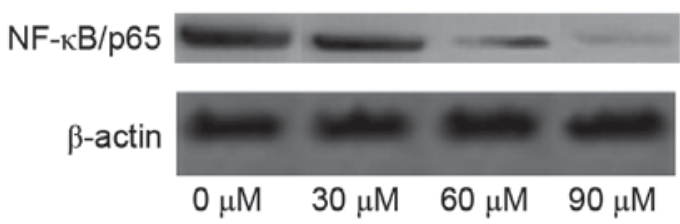

B

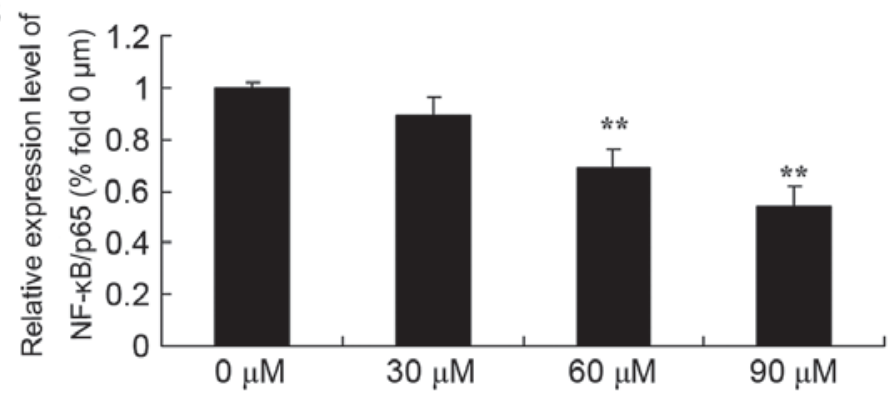

Figure 8. Berberine hydrochloride treatment inhibits $\mathrm{NF}-\kappa \mathrm{B}$ protein expression levels in A549 cells. Western blotting and statistical analysis were performed in order to evaluate the expression level of NF- $\mathrm{B}$ protein in berberine hydrochloride treated A549 cells. ${ }^{* *} \mathrm{P}<0.01$, compared with the $0 \mu \mathrm{M}$ berberine hydrochloride treatment group. $\mathrm{NF}-\kappa \mathrm{B}$, nuclear factor $\kappa \mathrm{B}$.

A

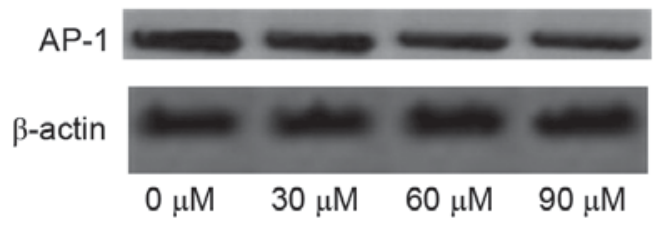

B

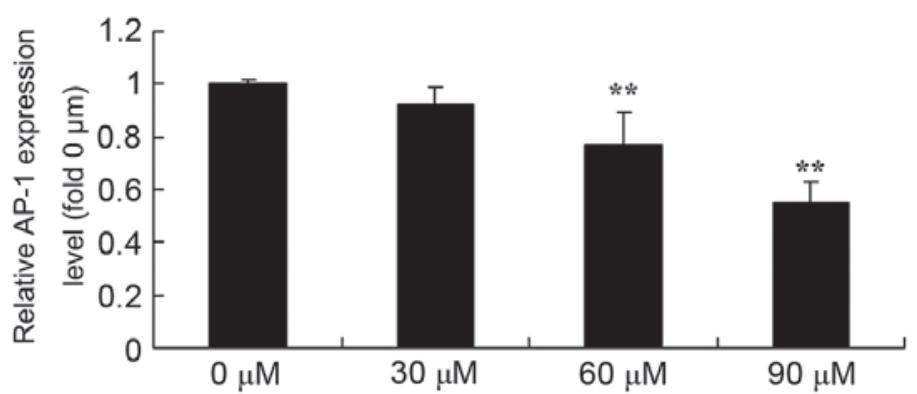

Figure 9. Berberine hydrochloride treatment inhibits AP-1 protein expression in A549 cells. Western blotting and statistical analysis were performed in order to evaluate the expression level of AP-1 protein in berberine hydrochloride treated A549 cells. ${ }^{* *} \mathrm{P}<0.01$, compared with the $0 \mu \mathrm{M}$ berberine hydrochloride treatment group. AP-1, transcription factor AP-1.

tumor metastasis into lymph glands or other tissues and the formation of metastatic tumors $(28,29)$. The expression levels of MMP-2 and MMP-9 were significantly increased in tumor cells, compared with normal tissues, and positively correlated with tumor invasion ability $(27,30,31)$. In the present study, a $24 \mathrm{~h}$ treatment with berberine hydrochloride significantly inhibited MMP-2 protein expression levels in A549 cells. Liu et al (27) suggested that berberine suppressed human aortic smooth muscle cells by decreasing the expression levels of MMP-2 and inhibiting the NF- $\mathrm{NB} / \mathrm{AP}-1$ signaling pathways. Therefore, berberine hydrochloride inhibition of lung cancer may occur primarily via the MMP-2 signaling pathway.

VEGF belongs to a group of endothelial growth factors mainly produced by tumor cells and intercellular substances (32). VEGF belongs to a group of endothelial growth factors mainly produced by tumor cells and intercellular substances. VEGF may promote the formation and development of novel blood vessels (29). Angiogenesis is essential to tumor growth, infiltration and metastasis, and it is regulated by a series of promotion and inhibition factors; one of the most important factors is VEGF, which is secreted by tumor cells in the growth stage (33). The expression level of VEGF in the sera of patients with lung cancer is significantly increased compared with in healthy patients, and is significantly higher in cancerous tissues and benign lesions, compared within healthy lung tissues (8). In the present study, berberine hydrochloride induced a significant upregulation of the VEGF signaling pathway in A549 cells. Zhang et al (30) demonstrated that berberine inhibits the expression of hypoxia-inducible factor $1 \alpha$ and increases the expression level of VEGF in prostate cancer. Therefore, the anticancer effect of berberine hydrochloride on A549 cells may occur via the activation of the VEGF signaling pathway.

Numerous genes are involved in the apoptosis of lung cancer and Bcl-2 is closely associated with Bax and NSCLC (34). The overexpression of the anti-apoptotic gene, $\mathrm{Bcl}-2$, and the low expression level of the apoptosis-promoting gene, Bax, inhibits cell apoptosis and extends the cell survival time, which is one of the underlying mechanisms of lung cancer (35). The abnormal expression level of Bax in NSCLC may be associated with to the occurrence, development and prognosis of NSCLC (36). In the present study, berberine hydrochloride significantly increased the activity of the Bcl-2/Bax signaling pathway in A549 cells. Xie et al (34) revealed that berberine induced apoptosis via the downregulation of $\mathrm{Bcl}-2$ in human breast cancer cells. Li et al (11) suggested that berberine hydrochloride inhibited the invasion of and promoted cell apoptosis in MDA-MB-231 cells through inactivation of the Jak2/NF- $\mathrm{B} / \mathrm{AP}-1$ signaling pathways. Thus, the suppression of Bcl-2/Jak2/NF- $\mathrm{B} / \mathrm{AP}-1$ expression levels were involved in the cell apoptosis induced by berberine hydrochloride.

In conclusion, berberine hydrochloride may be a possible anticancer therapeutic strategy, as it inhibits cell proliferation and promotes apoptosis of NSCLC cells via suppression of the MMP-2, Bcl-2/Bax and Jak2/VEGF/NF-кB/AP-1 signaling pathways. Therefore, the results of the present study suggest that berberine hydrochloride may be an effective and safe therapeutic candidate drug for treating NSCLC in humans. 


\section{References}

1. Chen HM, Tsai CM, Wu YC, Lin KC and Lin CC: Randomised controlled trial on the effectiveness of home-based walking exercise on anxiety, depression and cancer-related symptoms in patients with lung cancer. Br J Cancer 112: 438-445, 2015.

2. Yun YH, Shon EJ, Yang AJ, Kim SH, Kim YA, Chang YJ, Lee J, Kim MS, Lee HS, Zo JI, et al: Needs regarding care and factors associated with unmet needs in disease-free survivors of surgically treated lung cancer. Ann Oncol 24: 1552-1559, 2013.

3. Welsh JW, Komaki R, Amini A, Munsell MF, Unger W, Allen PK, Chang JY, Wefel JS, McGovern SL, Garland LL, et al: Phase II trial of erlotinib plus concurrent whole-brain radiation therapy for patients with brain metastases from non-small-cell lung cancer. J Clin Oncol 31: 895-902, 2013.

4. Schuette W, Krzakowski MJ, Massuti B, Otterson GA, Lizambri R, Wei H, Berger DP and Chen Y: Randomized phase II study of palifermin for reducing dysphagia in patients receiving concurrent chemoradiotherapy for locally advanced unresectable non-small cell lung cancer. J Thorac Oncol 7: 157-164, 2012.

5. Takigawa N, Kiura K, Segawa Y, Hotta K, Tamaoki A, Tokuda Y, Nagata T, Watanabe K, Gemba K, Moritaka T, et al: Benefits and adverse events among elderly patients receiving concurrent chemoradiotherapy for locally advanced non-small cell lung cancer: Analysis of the Okayama Lung Cancer Study Group trial 0007. J Thorac Oncol 6: 1087-1091, 2011.

6. Li J, Hu YM, Du YJ, Zhu LR, Qian H, Wu Y and Shi WL: Expressions of MUC1 and vascular endothelial growth factor mRNA in blood are biomarkers for predicting efficacy of gefitinib treatment in non-small cell lung cancer. BMC Cancer 14 848, 2014.

7. Laack E, Scheffler A, Burkholder I, Boeters I, Andritzky B, Schuch G, Görn M, Vohwinkel G, Edler L, Fiedler W and Hossfeld DK: Pretreatment vascular endothelial growth factor (VEGF) and matrix metalloproteinase-9 (MMP-9) serum levels in patients with metastatic non-small cell lung cancer (NSCLC). Lung Cancer 50: 51-58, 2005.

8. Li H, Takayama K, Wang S, Shiraishi Y, Gotanda K, Harada T, Furuyama K, Iwama E, Ieiri I, Okamoto I and Nakanishi Y: Addition of bevacizumab enhances antitumor activity of erlotinib against non-small cell lung cancer xenografts depending on VEGF expression. Cancer Chemother Pharmacol 74: 1297-1305, 2014.

9. Peng WJ, Zhang JQ, Wang BX, Pan HF, Lu MM and Wang J: Prognostic value of matrix metalloproteinase 9 expression in patients with non-small cell lung cancer. Clin Chim Acta 413: 1121-1126, 2012.

10. Siejka A, Barabutis N and Schally AV: GHRH antagonist inhibits focal adhesion kinase (FAK) and decreases expression of vascular endothelial growth factor (VEGF) in human lung cancer cells in vitro. Peptides 37: 63-68, 2012.

11. Li X, Zhao SJ, Shi HL, Qiu SP, Xie JQ, Wu H, Zhang BB, Wang ZT, Yuan JY and Wu XJ: Berberine hydrochloride IL-8 dependently inhibits invasion and IL-8-independently promotes cell apoptosis in MDA-MB-231 cells. Oncol Rep 32: 2777-2788, 2014.

12. Wang HY, Yu HZ, Huang SM and Zheng YL: p53, Bcl-2 and cox-2 are involved in berberine hydrochloride-induced apoptosis of HeLa229 cells. Mol Med Rep 14: 3855-3861, 2016.

13. Li HL, Wu H, Zhang BB, Shi HL and Wu XJ: MAPK pathways are involved in the inhibitory effect of berberine hydrochloride on gastric cancer MGC 803 cell proliferation and IL-8 secretion in vitro and in vivo. Mol Med Rep 14: 1430-1438, 2016.

14. Singh IP and Mahajan S: Berberine and its derivatives: A patent review (2009-2012). Expert Opin Ther Pat 23: 215-231, 2013.

15. Tan W, Li Y, Chen M and Wang Y: Berberine hydrochloride: Anticancer activity and nanoparticulate delivery system. Int J Nanomedicine 6: 1773-1777, 2011.

16. Diogo CV, Machado NG, Barbosa IA, Serafim TL, Burgeiro A and Oliveira PJ: Berberine as a promising safe anti-cancer agent-is there a role for mitochondria? Curr Drug Targets 12: 850-859, 2011.

17. Kim HS, Kim MJ, Kim EJ, Yang Y, Lee MS and Lim JS: Berberine-induced AMPK activation inhibits the metastatic potential of melanoma cells via reduction of ERK activity and COX-2 protein expression. Biochem Pharmacol 83: 385-394, 2012.

18. $\mathrm{Lu} \mathrm{W}, \mathrm{Du} \mathrm{S}$ and Wang J: Berberine inhibits the proliferation of prostate cancer cells and induces $\mathrm{G}_{0} / \mathrm{G}_{1}$ or $\mathrm{G}_{2} / \mathrm{M}$ phase arrest at different concentrations. Mol Med Rep 11: 3920-3924, 2015.
19. Tamura M, Oda M, Matsumoto I, Tsunezuka Y, Kawakami K, Ohta Y and Watanabe G: The combination assay with circulating vascular endothelial growth factor (VEGF)-C, matrix metalloproteinase-9, and VEGF for diagnosing lymph node metastasis in patients with non-small cell lung cancer. Ann Surg Oncol 11: 928-933, 2004

20. Gridelli C, Rossi A, Di Maio M, Leo S, Filipazzi V, Favaretto AG, Burgio MA, Cinieri S, Bianco R, Ciardiello F, et al: Rationale and design of MILES-3 and MILES-4 studies: Two randomized phase 3 trials comparing single-agent chemotherapy versus cisplatin-based doublets in elderly patients with advanced non-small-cell lung cancer. Clin Lung Cancer 15: 166-170, 2014.

21. Kentepozidis N, Kotsakis A, Soultati A, Agelaki S, Christophylakis Ch, Agelidou M, Chelis L, Papakotoulas P, Vamvakas L, Zafiriou Z, et al: Docetaxel plus cisplatin and bevacizumab for untreated patients with advanced/metastatic non-squamous non-small-cell lung cancer: A multicenter phase II study of the Hellenic Oncology Research Group. Cancer Chemother Pharmacol 71: 605-612, 2013.

22. Tan W, Zhong Z, Wang S, Suo Z, Yang X, Hu X and Wang Y: Berberine regulated lipid metabolism in the presence of $\mathrm{C} 75$, compound C, and TOFA in breast cancer cell line MCF-7. Evid Based Complement Alternat Med 2015: 396035, 2015.

23. Guamán Ortiz LM, Croce AL, Aredia F, Sapienza S, Fiorillo G, Syeda TM, Buzzetti F, Lombardi P and Scovassi AI: Effect of new berberine derivatives on colon cancer cells. Acta Biochim Biophys Sin (Shanghai) 47: 824-833, 2015.

24. Chen Q, Qin R, Fang Y and Li H: Berberine sensitizes human ovarian cancer cells to cisplatin through miR-93/PTEN/Akt signaling pathway. Cell Physiol Biochem 36: 956-965, 2015.

25. Wang R, Ke ZF, Wang F, Zhang WH, Wang YF, Li SH and Wang LT: GOLPH3 overexpression is closely correlated with poor prognosis in human non-small cell lung cancer and mediates its metastasis through upregulating MMP-2 and MMP-9. Cell Physiol Biochem 35: 969-982, 2015.

26. Dong QZ, Wang Y, Tang ZP, Fu L, Li QC, Wang ED and Wang EH: Derlin-1 is overexpressed in non-small cell lung cancer and promotes cancer cell invasion via EGFR-ERK-mediated up-regulation of MMP-2 and MMP-9. Am J Pathol 182: 954-964, 2013.

27. Liu SJ, Yin CX, Ding MC, Xia SY, Shen QM and Wu JD: Berberine suppresses in vitro migration of human aortic smooth muscle cells through the inhibitions of MMP-2/9, u-PA, AP-1, and NF-kappaB. BMB Rep 47: 388-392, 2014.

28. Cepeda MA, Evered CL, Pelling JJ and Damjanovski S: Inhibition of MT1-MMP proteolytic function and ERK1/2 signalling influences cell migration and invasion through changes in MMP-2 and MMP-9 levels. J Cell Commun Signal 11: 167-179, 2017.

29. Andorfer P, Heuwieser A, Heinzel A, Lukas A, Mayer B and Perco P: Vascular endothelial growth factor A as predictive marker for mTOR inhibition in relapsing high-grade serous ovarian cancer. BMC Syst Biol 10: 33, 2016.

30. Zhang Q, Zhang C, Yang X, Yang B, Wang J, Kang Y, Wang Z, Li D, Huang G, Ma Z, et al: Berberine inhibits the expression of hypoxia induction factor-1alpha and increases the radiosensitivity of prostate cancer. Diagn Pathol 9: 98, 2014.

31. Hrabec E, Strek M, Nowak D, Greger J, Suwalski M and Hrabec Z: Activity of type IV collagenases (MMP-2 and MMP-9) in primary pulmonary carcinomas: A quantitative analysis. J Cancer Res Clin Oncol 128: 197-204, 2002.

32. Kim YR and Hong SH: Association between the polymorphisms of the vascular endothelial growth factor gene and metabolic syndrome. Biomed Rep 3: 319-326, 2015.

33. Sandler A, Hirsh V, Reck M, von Pawel J, Akerley W and Johnson DH: An evidence-based review of the incidence of CNS bleeding with anti-VEGF therapy in non-small cell lung cancer patients with brain metastases. Lung Cancer 78: 1-7, 2012.

34. Xie J, Xu Y, Huang X, Chen Y, Fu J, Xi M and Wang L: Berberine-induced apoptosis in human breast cancer cells is mediated by reactive oxygen species generation and mitochondrial-related apoptotic pathway. Tumour Biol 36: 1279-1288, 2015.

35. Lu B, Li Y, Li H, Zhang Y, Xu J, Ren L, Fu S and Zhou Y: Bax inhibitor-1 is overexpressed in non-small cell lung cancer and promotes its progression and metastasis. Int J Clin Exp Pathol 8: 1411-1418, 2015.

36. Hansakul P, Aree K, Tanuchit S and Itharat A: Growth arrest and apoptosis via caspase activation of dioscoreanone in human non-small-cell lung cancer A549 cells. BMC Complement Altern Med 14: 413, 2014. 